Case Report

\title{
Management of Second Trimester Fetal Demise in a Noncommunicating Uterine Horn
}

\author{
R. Tyler Hillman, Homer G. Chin, and Sheila K. Mody \\ Department of Reproductive Medicine, UCSD Medical Center, 200 W. Arbor Drive, San Diego, CA 92103, USA \\ Correspondence should be addressed to R. Tyler Hillman; rhillman@ucsd.edu
}

Received 2 April 2015; Accepted 27 May 2015

Academic Editor: Stefan P. Renner

Copyright (C) 2015 R. Tyler Hillman et al. This is an open access article distributed under the Creative Commons Attribution License, which permits unrestricted use, distribution, and reproduction in any medium, provided the original work is properly cited.

Müllerian anomalies are uncommon but when present they can increase the risk of obstetrical complications. Anomalies such as bicornuate and unicornuate uterus can also increase the surgical risks of pregnancy termination. The diagnostic approach and surgical management must be individualized for each patient so that the termination procedure is safe and preserves fertility. We present a case of a patient with a 17-week pregnancy with fetal demise in a noncommunicating right uterine horn. Laparotomy and hysterotomy were required for evacuation of the fetus. The use of appropriate imaging studies to diagnose suspected uterine anomalies and a flexible and individualized operative strategy are essential for reducing complications associated with the termination of abnormal or unintended pregnancies in women with Müllerian anomalies.

\section{Introduction}

As many as $10 \%$ of women in an unselected population have developmental anomalies of Müllerian structures [1]. Müllerian anomalies such as unicornuate uterus, bicornuate uterus, and uterine didelphys are caused by defects in the formation or fusion of bilateral paramesonephric structures and these defects increase the risk of early pregnancy loss, preterm birth, and fetal malpresentation [1]. Müllerian anomalies are usually not detectable by clinical examination and diagnosis often requires pelvic imaging. Even minor Müllerian anomalies may increase the complexity and morbidity associated with the surgical management of abnormal or unintended pregnancy, especially when unrecognized $[2,3]$. In the extreme case of pregnancy in a noncommunicating uterine horn, safe pregnancy management depends upon early and accurate diagnosis to prevent complications such as uterine rupture $[4,5]$. We present a case of a patient with a second trimester fetal demise in a noncommunicating uterine horn.

\section{Case Presentation}

A 19-year-old G1P0 female with a fetal demise at 17 weeks and 4 days of gestational age presented to the emergency department (ED) with light vaginal bleeding. An ultrasound examination performed one week prior to her presentation demonstrated a nonviable fetus in the right horn of a suspected bicornuate uterus. The patient was referred for dilation and evacuation and was awaiting her appointment at the time of her ED visit. In the ED the patient was hemodynamically stable and was not actively bleeding. Since dilation and evacuation were already planned for the following day, an attempt was made to insert osmotic cervical dilators into the cervical canal under ultrasound guidance. A cervical dilator was easily advanced into the left uterine horn; however, the dilator could not be advanced into the horn that contained the fetus. The procedure was therefore discontinued.

A pelvic MRI was ordered and results did not reveal a communication between the cervix and the gravid right uterine horn (Figure 1). Although MRI has limitations in the diagnosis of rudimentary uterine horns, it is among the most accurate noninvasive diagnostic modalities [6]. The patient was counseled that the fetus could not be removed via dilation and evacuation. We recommended laparotomy with hysterotomy and the patient consented to proceed.

At surgery, an infraumbilical vertical midline skin incision was made and exploration of the pelvis revealed an enlarged right uterine horn (Figure 2(a)). Hysterotomy was 


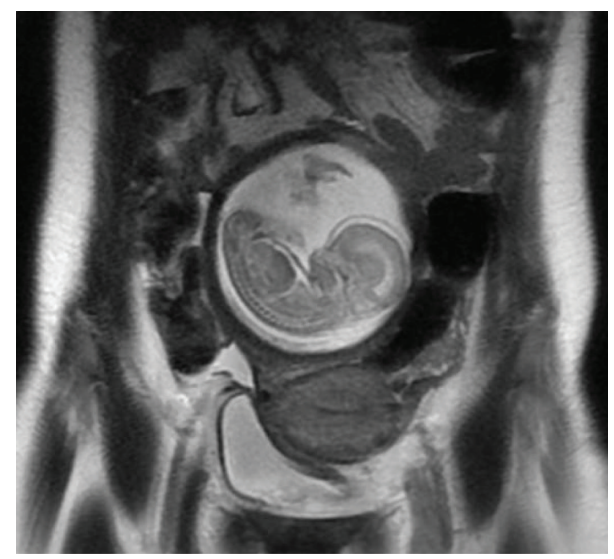

FIGURE 1: Preoperative MRI showing fetus in right uterine horn with no visible channel between left and right uterine horn.

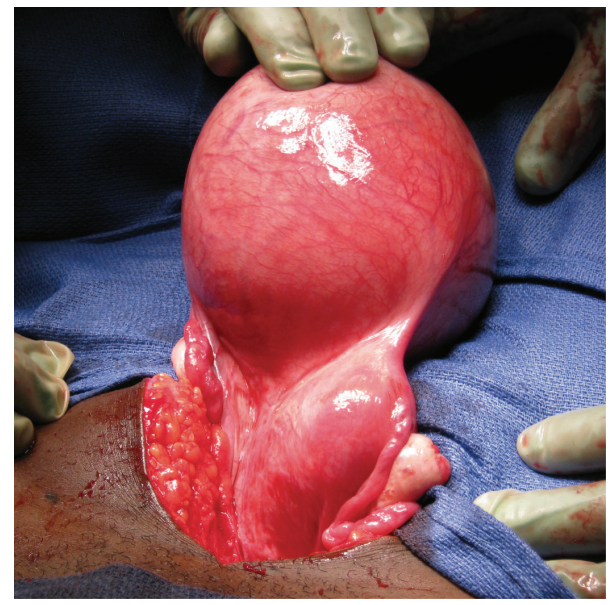

(a)

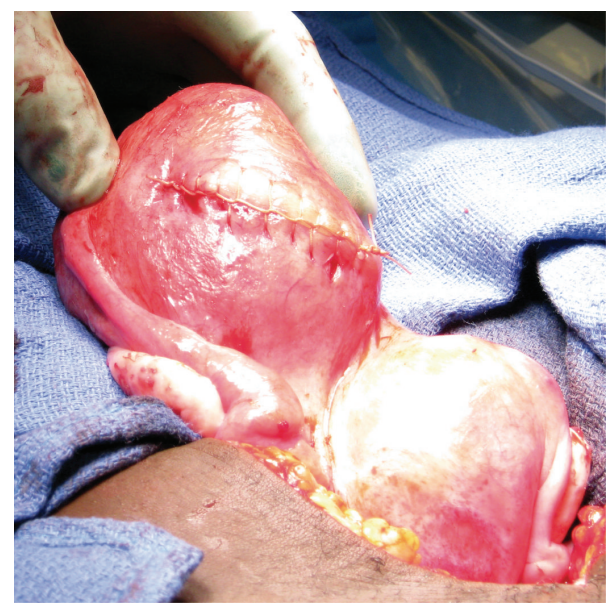

(b)

Figure 2: The gross appearance of the bicornuate uterus during surgery: (a) before uterine evacuation, with fetus in situ, and (b) after removal of the fetal remains and hysterotomy closure.

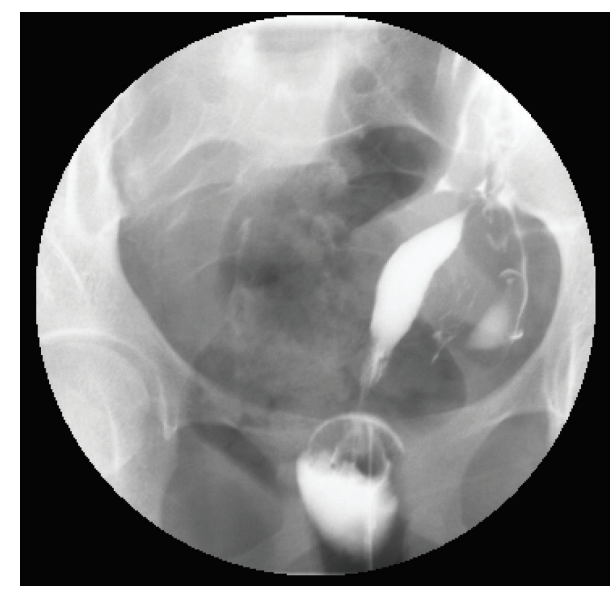

FIgURE 3: A hysterosalpingogram demonstrating contrast extravasation through the left uterine horn and fallopian tube.

performed with a transverse incision and the fetus was evacuated with placenta, without difficulty. Palpation of the uterine cavity did not reveal communication with either the cervical canal or the left uterine horn. The hysterotomy was closed in three layers with delayed absorbable suture. Following evacuation and contraction of the right uterine horn, the external aspect of the uterus appeared bicornuate (Figure 2(b)). The abdominal incision was closed.

Pathologic examination revealed an anatomically normal fetus. The patient was discharged home after an uneventful postoperative recovery. The patient underwent insertion of an etonogestrel implant (Nexplanon) at her postoperative appointment. Three months after her surgery, the patient underwent hysterosalpingography (HSG), which revealed a left unicornuate uterus without communication with the right uterine horn (Figure 3).

\section{Discussion}

If products of conception are not obtained during surgical management of fetal demise or pregnancy termination the presence of a uterine anomaly must be considered. Bedside ultrasound may not be sufficient to exclude the presence of a uterine anomaly [7]. In the case of a noncommunicating uterine horn, insertion of cervical dilators may increase the risk of uterine perforation. When difficulty is encountered, the use of additional imaging modalities such as MRI should be considered.

Pregnancy in a noncommunicating uterine horn is rare (1 in 76,000 to 1 in 150,000 live births), making this an unusual diagnosis in women presenting for pregnancy termination $[4$, 8]. When diagnosed in the nonemergent setting, pregnancy in a rudimentary uterine horn should be considered ectopic and managed as an abnormal pregnancy due to the high risk of uterine rupture as well as other maternal complications [4]. Hysterotomy to evacuate a fetus in an anomalous uterus should be considered for advanced gestations and when alternative approaches fail $[3,9]$. 
The absence of communication between this patient's external cervix and the gravid uterine horn, as confirmed by postevacuation HSG (Figure 3), suggests the possibility that fertilization was the result of transperitoneal sperm migration which may account for as many as 50\% of pregnancies occurring in women with such anomalies [10]. Removal of the rudimentary horn is therefore recommended because of the high likelihood of recurrent pregnancy in this location $[3,4]$. Removal of the rudimentary horn was deferred in this case until the absence of a cervical communication could be confirmed by HSG.

\section{Disclosure}

Sheila K. Mody is a MERCK Nexplanon trainer.

\section{Conflict of Interests}

The authors do not report any potential conflict of interests.

\section{References}

[1] Y. Y. Chan, K. Jayaprakasan, A. Tan, J. G. Thornton, A. Coomarasamy, and N. J. Raine-Fenning, "Reproductive outcomes in women with congenital uterine anomalies: a systematic review," Ultrasound in Obstetrics and Gynecology, vol. 38, no. 4, pp. 371-382, 2011.

[2] K. Jermy, O. Oyelese, and T. Bourne, "Uterine anomalies and failed surgical termination of pregnancy: the role of routine preoperative transvaginal sonography," Ultrasound in Obstetrics and Gynecology, vol. 14, no. 6, pp. 431-433, 1999.

[3] L. M. Goldthwaite and S. B. Teal, "Controversies in family planning: pregnancy termination in women with uterine anatomic abnormalities," Contraception, vol. 90, no. 4, pp. 460-463, 2014.

[4] S. Siwatch, R. Mehra, D. K. Pandher, and A. Huria, "Rudimentary horn pregnancy: a 10-year experience and review of literature," Archives of Gynecology and Obstetrics, vol. 287, no. 4, pp. 687-695, 2013.

[5] S. Thakur, A. Sood, and C. Sharma, "Ruptured noncommunicating rudimentary horn pregnancy at 19 weeks with previous cesarean delivery: a case report," Case Reports in Obstetrics and Gynecology, vol. 2012, Article ID 308476, 4 pages, 2012.

[6] K. Devine, T. McCluskey, M. Henne, A. Armstrong, A. M. Venkatesan, and A. DeCherney, "Is magnetic resonance imaging sufficient to diagnose rudimentary uterine horn? A case report and review of the literature," Journal of Minimally Invasive Gynecology, vol. 20, no. 4, pp. 533-536, 2013.

[7] J. S. Pellerito, S. M. McCarthy, M. B. Doyle, M. G. Glickman, and A. H. DeCherney, "Diagnosis of uterine anomalies: relative accuracy of MR imaging, endovaginal sonography, and hysterosalpingography," Radiology, vol. 183, no. 3, pp. 795-800, 1992.

[8] G. G. Nahum, "Rudimentary uterine horn pregnancy. The 20th-century worldwide experience of 588 cases," Journal of Reproductive Medicine for the Obstetrician and Gynecologist, vol. 47, no. 2, pp. 151-163, 2002.

[9] G. B. Lazenby, C. Huang, A. M. Rahall, and N. S. Fogelson, "Pregnancy termination via laparotomy in a woman with bicornuate uterus," Contraception, vol. 75, no. 3, pp. 241-243, 2007.
[10] G. G. Nahum, H. Stanislaw, and C. McMahon, "Preventing ectopic pregnancies: how often does transperitoneal transmigration of sperm occur in effecting human pregnancy?" BJOG, vol. 111, no. 7, pp. 706-714, 2004. 


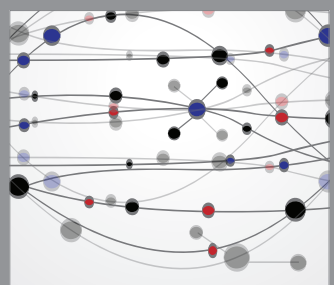

The Scientific World Journal
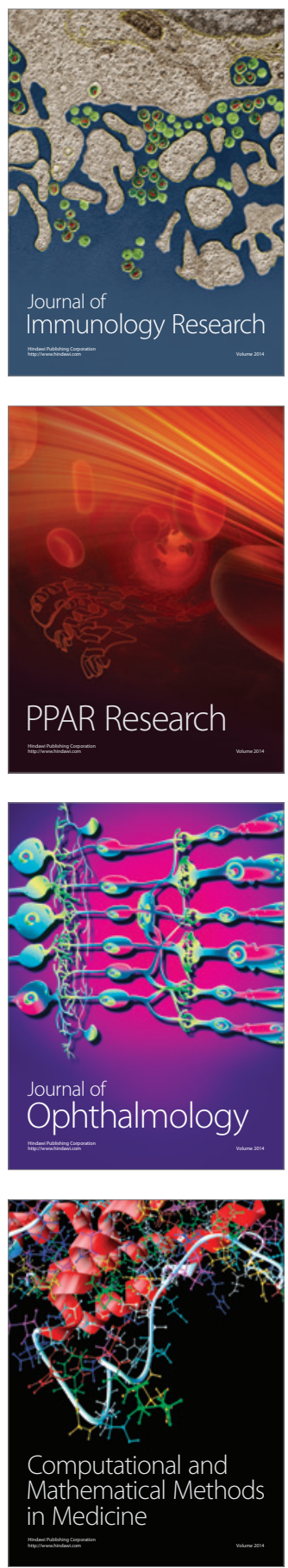

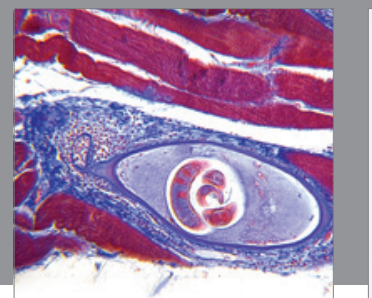

Gastroenterology

Research and Practice
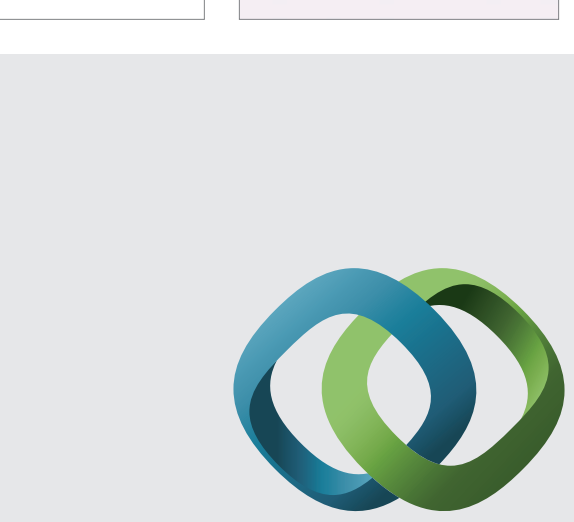

\section{Hindawi}

Submit your manuscripts at

http://www.hindawi.com
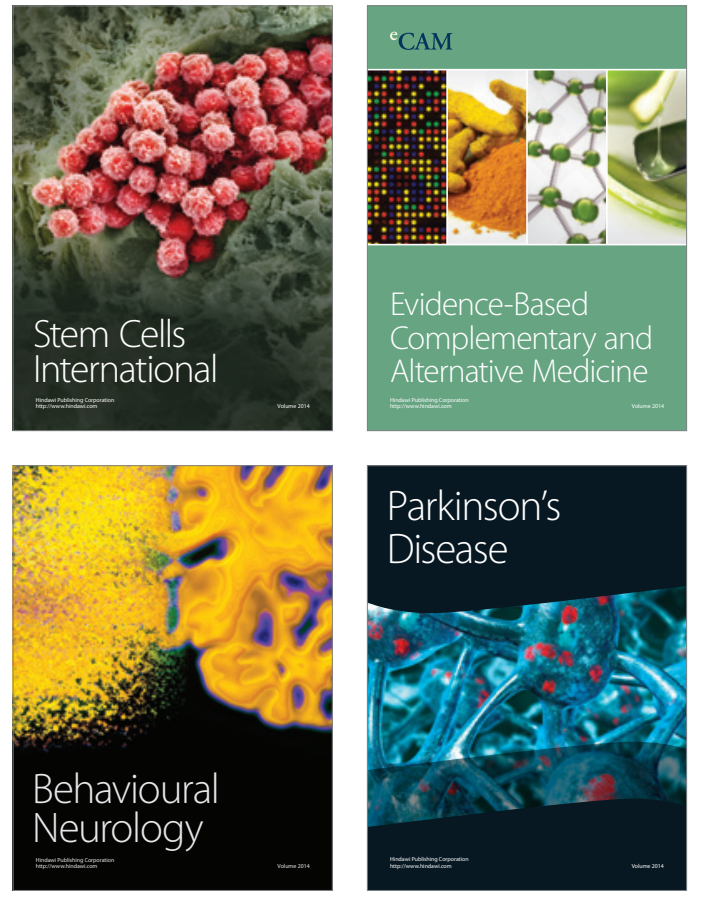
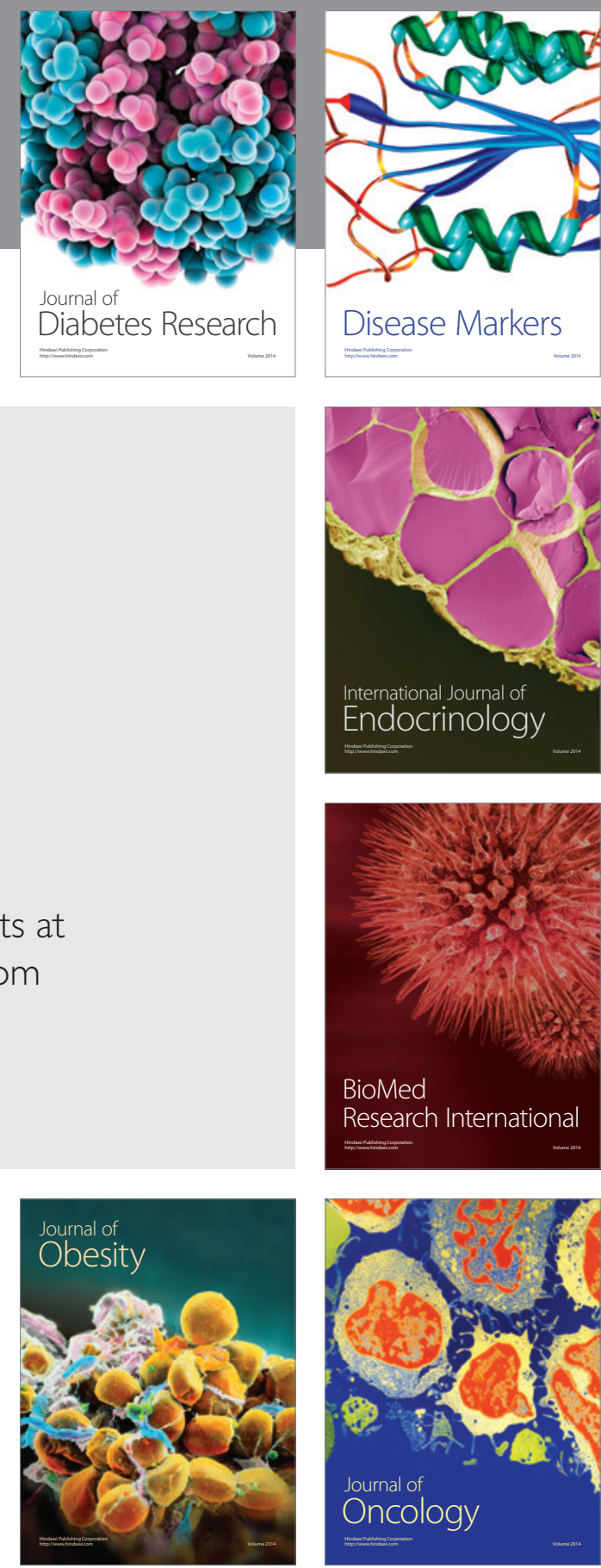

Disease Markers
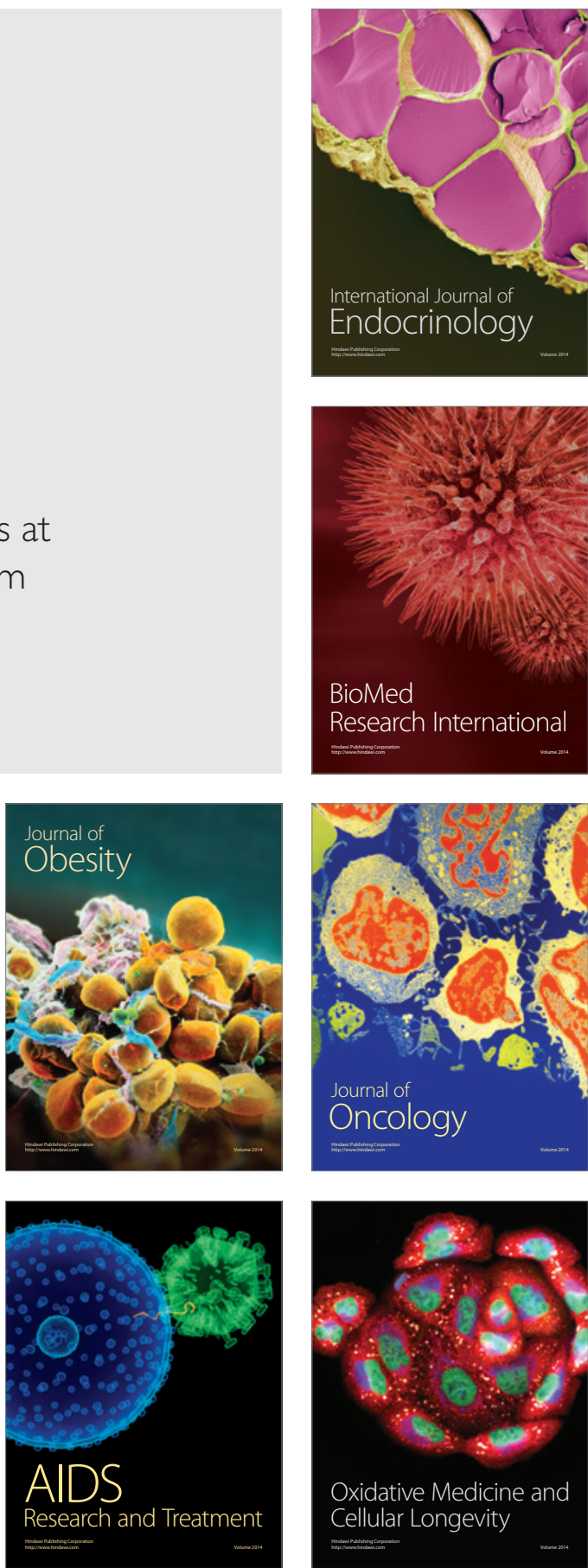